\title{
Reverse Metadesign: Pedagogy and Learning Tools for Teaching The Fashion Collection Design Process Online
}

\author{
Daria Casciani, Chiara Colombi, Federica Vacca
}

Design Department, Politecnico di Milano, Italy.

\begin{abstract}
The present article discusses the experience of redesigning the pedagogy and learning tools of a pillar course at the School of Design of Politecnico di Milano, the Metadesign studio course. Metadesign is a design methodology that leads to the concept definition of a new product or service through a research process that synthesizes design goals, technological and productive constraints, market context, and consumption trends for a consumers' group of reference. It represents a unique methodological approach characterizing a design education as it provides a consolidated research practice able to support the design process. The course structure foresees the reconstruction in phases and the development of all the contextual elements-product, space, service, communication artifact, etc. - that come into relation with the to-bedesigned object and influence its characteristics. This process enables creating the "abacus" of components to use in a design activity. Considering the everincreasing need to reshape the whole education system because of the paradigmatic change pushed by digital transformation and the urgency for ondistance courses posed by the COVID-19 emergency, the article presents a renewed "reversed" course structure. It highlights strengths and opportunities for further improvements representing a solid base for innovating a fashion design education.
\end{abstract}

Keywords: Metadesign; fashion design; learning-by-doing; reflection-inaction; deductive reflection; virtual learning environments. 


\section{Introduction to Metadesign for Fashion: Pedagogical Principles and Approaches}

Metadesign (Van Onck, 1964) is a methodological approach that aims to provide students with preliminary design skills to lead the concept definition of a new product or service considering a system of socio-cultural, production and market opportunities, and constraints. This methodology represents the core of design education at Politecnico di Milano. In the 2nd year of all the bachelor's degree programs at the Design School of Politecnico di Milano, a design studio focuses on it.

The Metadesign studio encompasses the entire design process, from research methods and tools for understanding the product system to the interpretative reading of the design context, up to the envision of a use scenario. Specifically, in the Fashion Design Program, Metadesign Studio aims to trace the entire design process that leads to the conceptualization of an apparel collection, covering the different phases, from research and analysis to concept generation, design, and presentation, towards methods and tools representative of the discipline.

The faculty team composition is interdisciplinary in terms of competencies, roles, and responsibilities. It includes both scholars, experts in managing the Metadesign process applied to the fashion design domain, and professionals skilled in all the phases concerning the development of an apparel collection, from research to design and production. This interdisciplinary composition guarantees the integration of an Academy-Industry perspective (Colombi \& Vacca, 2016) by offering students, grouped in working teams, the opportunity to develop their own design skills through the experimentation of a real case study (Bertola et al., 2017).

The studio-based didactic experience is structured in two subsequent levels. The first one has a theoretical-analytical focus, and it is organized in theoretical lectures, instrumental lectures, and seminars with guest speakers. It mainly involves a creative and critical thinking approach (Crane, 1983; Anderson, 1990), encouraging learners to develop systemic and logical reasoning, frame market context, examine technological and productive constraints, and understand consumption trends linked to the very fashion product. The second one presents a conceptual focus on a reflection-in-action approach (Stewart \& Colombi, 2015) characterized by two crucial pedagogical methods.

On the one hand, the learning-by-doing approach, where students' participation in practical activities, complemented by a critical and strategic thinking method, is preferred (Shön, 1983). On the other hand, the participatory learning approach, where learners are encouraged to actively participate within the working team and in constant dialogue and reflection with faculty, favoring a learning process based on sharing knowledge in the process and practice (Orr \& Shreve, 2017). This second level provides for a team assignment throughout the semester. The assignment is divided into intermediate working phases and is partially 
developed by students during the working hours in class and partially during at-home working hours. Therefore, the objective of this approach is to constantly monitor and train the different teams in the simulation of the professional activity of an actual design department.

\section{Reverse Metadesign: Redesigning the Fashion Design Process}

Until the 2019-2020 academic year, the Metadesign studio was almost entirely held in person. The in-person format included instrumental lectures taught by the faculty and seminars with guest experts in the field to offer detailed and timely contents for specific phases of the team assignment.

In line with the ever-increasing need to reshape the whole fashion education system through the paradigms of digital transformation and, more in general, to innovate the design education acquiring new pedagogical tools, already for the 2018-2019 academic year, the theoretical lectures related to the Metadesign theory were transferred into an ad-hoc designed Massive Online Open Course (MOOC), entitled "Introducing Metadesign." The MOOC provides fundamental definitions and references for the topic. It presents all the design phases/processes and activities, teaching students to shift from a basic problem solving to a problem setting and problem finding attitude to structure the pre-project research.

The proposed blended methodology introduced innovative teaching and learning approaches that were expanded on the following course components. According to a reflection-in-action path (Stewart \& Colombi, 2015), a consistent number of hours of the in-person format were allocated to in-class activities to favor learners' understanding towards a participative approach and inductive exploration. In-class activities were meant to support teams in the concept development of a Spring-Summer womenswear collection for a Ready-to-Wear brand selected and assigned to each team by the faculty. For this purpose, the six months long assignment was divided into three different phases (Bertola et al., 2017).

The first one, Scenario Design, was grounded in between observation and reflection on the actual context. It dealt with a preliminary analysis of the assigned brand's values and stylistic identity to abstract in-depth iconographic research into three different perceptual scenarios (moodboards) — which define colors, shades, touches, and atmospheres - , and outlining the ideal consumer and her lifestyle.

The second one, Product and Concept Design, concerned the synthesis of the brand's distinctive stylistic into new and original design solutions thanks to the definition of the main features of the collection, such as cuts, constructions, volumes, lengths, fittings, details, etc.

In this phase, key-outfits designs, fabric customizations, graphic motifs development, embellishments experimentations were the core activities of the Metadesign studio required 
and developed by students. The third and last phase, Merchandise Planning, covered the process of systematization, reflection, and abstraction on the outcomes of the previous steps, activating the second loop of a deeper understanding of the experienced process.

This phase materialized the ideal structure of a collection organized into three main occasions of use (work, leisure, special occasion) to complete an ideal wardrobe. The merchandising plan was then achieved, starting from developing key ideas and key items representing the three scenarios/lines defined in the first two phases. Students designed alternative or complementary typologies of items, complemented by color-fabric options, to offer a balanced mix of essential, fashionable, and carry-over items.

The learning process, structured as described above, adopted a methodological approach based on inductive practices, which, starting from a direct experience of the design practice, allow the student to reflect on the performed and then observed activities. This approach aims to abstract practices, and therefore to codify methodologies, leading to the acquisition of new knowledge. Due to the COVID-19 pandemic, the structure of the Metadesign studio needed a significant redesign by moving from in-person to on-distance learning.

The previous efforts of transferring theoretical contents into a MOOC format were not sufficient to guarantee a sustainable learning model for a design studio. The learning-bydoing approach needs to be experienced to learn a design methodology.

Therefore, it was necessary to reverse the methodological process of the team assignment, rethinking not only the structure and phases of the studio but completely redesigning the contents learning path. The "Reverse Metadesign" format proposed for the 2020-2021 academic year is based on a deductive process based on the assumption that the analysis and subsequent breakdown of a virtuous process already carried out would allow the students to understand and codify the design processes and then to replicate them.

The initial project phase, Introducing the Brand, focused both on analyzing an assigned RTW brand - aimed at investigating brand strategy, market position, and permanent stylistic codes - and on the reading and decoding of a specific apparel collection.

Through a process of deductive reflection of the actual product, this phase had the main objective of (i) recognizing the stories/lines of inspiration developed by the design team of the brand, recognizing the main visual elements, and translating them into moodboards; (ii) pinpointing the seasonal stylistic codes, such as colors, textures, shapes, finishes; and (iii) finally identifying the Stock Keeping Units (SKUs) of collection, organizing them by typologies.

The subsequent two phases of the project concerned the decoding of the brand identity and the design strategies activated by the very brand. Firstly, students, also in this case organized in teams, were asked to develop a critical analysis of the plan of the collection architecture 
(Reverse Merchandising phase) based on the brand identity, values, positioning, ideal customer, etc. Secondly, they were asked to propose a product development strategy (Product Design phase) to complement the collection coherently with the brand's one. Students had to use and redesign colors, fabrics, and embellishments consistently with the brand identity, the product mix of the analyzed collection, and the lifestyles of the ideal consumer.

\section{Interaction and Engagement in Distance Learning}

An essential part of the learning happens in allowing interaction and engagement intended as "the amount of physical and psychological energy that the student devotes to the academic experience" (Astin, 1984) among student-teacher, student-student, and student-content to ensure a connected student experience (Moore 1989). While some studies have not found a clear relationship between engagement and learning outcomes (Axelson \& Flick, 2010: 42), many researchers have argued that there are unequivocal links between engagement and students' learning and achievements (Kahn, 2014; Sinatra, Heddy, \& Lombardi, 2015).

Engagement is much more important in on-distance, and online learning, where high students drop out, could be critical. The intellectual interaction with contents should be enhanced by student-teacher (e.g., stimulating, counseling, encouraging, coaching students) and student-student engagement (e.g., allowing interaction between peers, in pair or group, with or without the presence of the instructor).

Focusing on the iterative reciprocal interaction between cognitive, behavioral, and environmental aspects, the social learning pedagogical model by Albert Bandura (1997) emphasizes the importance of exploiting peer-to-peer learning to reach educational goals and to grow independence and higher personalized learning experiences (Bowen et al., 2014).

\section{Creativity Management in Distance Learning}

As part of the innovation processes and activities, creativity derives both from intraindividual components (e.g.task motivation, domain-relevant skills, and creative strategies) and also from the social environment components (e.g., collaboration activities and the communication pattern characteristics) (Amabile, 1996). With online education, digital environments should support students' creative design processes, particularly in the conceptual phase of design, to boost knowledge gathering, sharing, and integration toward the generation of creative ideas (Greene, 2002).

In this paper, we focus on digital environments enhancing social creativity related to social interaction allowed by collaborative digital tools that support brainstorming processes (e.g., accessing information and pieces of knowledge and sharing experiences, ideas, resources, or 
responsibilities). In this regard, research states (Hulsheger et al., 2009) that creativity increases when there is a higher level of communication among the team members to support fruitful collaborative synchronous and asynchronous sessions for idea generation. Furthermore, these digital spaces allow users/groups to exchange contents and share materials via visual supports communication (e.g., mapping, images, diagrams) (Wang et al. 2010).

\section{Virtual Learning Environments (VLEs) and Digital Tools}

A combination of VLEs and digital tools supported the three levels of interaction and engagement toward creativity in the course. Digital tools were organized to handle a subset of learning management goals such as students' participation, interaction, and creative brainstorming to design digital fashion moodboards. For the sake of simplicity, we divided the tools (e.g., course space repository, digital e-classrooms, and group e-rooms and collaboration tools for student teamwork.) into distinct ones by presenting their affordances and limitations as separated. However, we acknowledge that their use will be not linear but mixed to help the digital learning experience positively.

\subsection{Course space repository}

Several VLEs allow lectures repository, archival, and fruition from students in remote digital modality. They also enable course management and are helpful to handle the logistical aspects of planning, scheduling, calendaring, and delivering content in a password-protected web environment. Besides, they support the traditional and prescriptive unidirectional communication between teacher and student through direct advisement, lecture, assignment sharing, and evaluation feedback communication.

\subsection{Digital E-classrooms and groups e-rooms}

These digital learning environments allow remote connection and synchronous interaction where both teaching and coaching can occur (teacher-student interaction) but studentcentered interactive discussions (e.g., Microsoft Teams, Zoom, Cisco Webex). In addition to the plenary e-classroom, digital free spaces allow students to meet and work in groups autonomously and collaboratively. In these two virtual environments, the facilitation and management of effective communication among team members and faculty are ensured through virtual meetings, instant messaging, screen sharing, and voice/video conferencing.

A speed dating exercise was organized to allow the students to present their ID charts sharing personality traits (e.g., strengths and weaknesses), study and cultural interests, working habits, and teamwork preferences. Students introduced themselves in a one-minute pitch in front of their peers to show their expertise and build their team autonomously through those virtual platforms. 


\subsection{Collaboration tools for student teamwork}

Collaboration tools aim to allow a collective space for students to co-create a shared and meaningful body of knowledge, to interact for brainstorming, and to creatively co-design a product/service/system (e.g., Miro, Mural, Conceptboard, Ziteboard, Stormboard). V

isual digital whiteboards are successfully used as project management tools to control the workflow of activities, as ideation tools to map and visualize ideas in early creative stages, and as co-design tools to allow groups to modify output and edit in real-time or asynchronously and to facilitate consensus building.

They are also management tools for resources, allowing archive project files that all group members can access. In place of online software for moodboards design (e.g., Pinterest, Moodzeer, Adobe Spark, Canva, GoMoodboard, Niice), groups of students used Miro as a white canvas to collaborate for brainstorming and visual storming toward the creation of the moodboards for each thematic line of the fashion brand they were assigned.

This co-generative process of moodboard making allows students to reflect on fashionrelated thematic lines through the cultural, material, and chromatic aspects. They first reflect on abstract values, adjectives, themes, cultural references, and symbols to build a shared visual mental map of keywords. Later they choose iconographic materials (e.g., photographs, patterns, materials, objects, colors, textures) to be preparatory for designing digital fashion moodboards.

\section{Conclusions}

Although the Reverse Metadesign process succeeded from a formal point of view in transferring the students the methodological processes behind the development of a clothing collection, the on-distance learning certainly limited some aspects of knowledge better explored in the traditional pedagogical model. First and foremost, the process of fabric and its embellishment knowledge.

Despite the increasing application of digital technology in the haptic perception of fabrics, the visual and tactile perception was completely missing. At the same time, it remains fundamental to learning the matter potentiality in terms of comfort, functionality, and expressive content. Secondly, on-distance learning has restricted the design participation of students in the whole Metadesign studio activities, limiting the exchange between different teams and inevitably reducing the interaction with the faculty in favor of virtual participation that is not always fully integrated and stimulated.

However, as the comprehension of pre-project activities was successful, the new pedagogical structure tested and here discussed represents a good starting point to build other didactic experiences with three objectives: i) developing solutions to introduce a more direct 
experience of fabrics, not only through haptic technological solutions but also with basic design exercises that stimulate perceptual understanding; ii) improving the structure of the product Development Phase to accompany the students' design activity better; iii) expanding further interactive and flipped activities for a more dynamic learning environment.

\section{References}

Amabile, T. M. (1996). Creativity in context. Boulder: Westview.

Anderson, G. A. (1990). Teaching creativity for professional growth and personal reward. NACTA Journal, 34 (4), 54-55.

Astin, A. W. (1984). Student involvement: A developmental theory for higher education. Journal of college student personnel, 25(4), 297-308.

Axelson, R. D., \& Flick, A. (2010). Defining Student Engagement. Change: The Magazine of Higher Learning, 43(1), 38-43. doi: 10.1080/00091383.2011.533096.

Bandura, A. (1977). Social Learning Theory. New York: General Learning Press.

Bertola P., Colombi C., \& Vacca F. (2017). From Product to Process in Fashion: Reading a Disciplinary Evolution Through The Metadesign. 10th International Conference of Education, Research and Innovation (ICERI 2017), 3554-3561.

Bowen, W. G., Chingos, M. M., Lack, K. A., \& Nygren, T. I. (2014). Interactive learning online at public universities: Evidence from a six-campus randomized trial. Journal of Policy Analysis and Management, 33(1), 94-111. doi.org/10.1002/pam.21728

Colombi, C., Vacca, F. (2016). Modeling new approaches in education: processes and toolkits. Vacca, F., Warshavski, T., (eds.) Interdisciplinary Research And Education Agenda: a Design Driven Perspective, Firenze: Mandragora.

Crane, L.D. (1983). Unlocking the brain's two powerful learning systems. Human Intelligence Newsletter, 4, (4), 7.

Greene, S. L. (2002). Characteristics of applications that support creativity. Communications of the ACM, 45(10), 100-104.

Hulsheger, U. R., Anderson, N., \& Salgado, J. F. (2009). Team-level predictors of innovation at work: A comprehensive meta-analysis spanning three decades of research. Journal of Applied Psychology, 94(5), 1128-1145.

Kahn, P. E. (2014). Theorising student engagement in higher education. British Educational Research Journal, 40(6), 1005-1018. doi: 10.1002/berj.3121.

Moore, M. G. (1989). Editorial: Three types of interaction. American Journal of Distance Education, 3(2), 1-7. doi: 10.1080/08923648909526659

Orr, S., Shreeve, A. (2017). Art and design pedagogy in higher education: knowledge, values and ambiguity in the creative curriculum. London: Routledge.

Shön, D. (1983). The Reflective Practitioner, London: Temple Smith.

Sinatra, G. M., Heddy, B. C., \& Lombardi, D. (2015). The Challenges of Defining and Measuring Student Engagement in Science. Educational Psychologist, 50(1), 1-13. doi: 10.1080/00461520.2014.1002924. 
Stewart, B., Colombi, C. (2015). Observation, reflection, and synthesis: pedagogical tools for teaching visual merchandising online. EDULEARN15 Proceedings, 2499-2506.

Van Onck, A. (1964). Metadesign. Edilizia Moderna, 85.

Wang, H. C., Cosley, D. M., \& Fussell, S. R. (2010). Idea expander: Supporting group brainstorming with conversationally triggered visual thinking stimuli. Proceedings of the 2010 ACM conference on computer supported cooperative work (CSCW'10), 103-106. doi: $10.1145 / 1718918.1718938$. 